\title{
6
}

\section{The Campaign that Wasn't: Tracking Public Opinion over the 44th Parliament and the 2016 Election Campaign}

\section{Simon Jackman and Luke Mansillo}

Elections are a game of inches where political parties attempt to move the needle of public opinion just enough to get their candidates across the line when all the ballots are counted. It is a high-stakes game that political parties play: parliamentary careers are on the line, as is the public policy trajectory the nation will take- both with profound consequences for citizens. Polls are often a source of evidence with which to praise or admonish various campaign strategies and tactics in pre-election prognostication and post-election soul-searching. ${ }^{1}$ Campaign directors, strategists, pollsters and the candidates themselves are often hailed as geniuses, dunces, heroes or villains in narratives about how elections are won or lost (Halperin and Heilemann 2010; Williams 1997). Generally, political scientists tend to be far more circumspect than journalists and commentators about the effects of campaigns on election outcomes. Decades of scholarship have shown that voter preferences are less pliable than is often supposed, the effects of political advertisements are at

1 The analytic and communication tools available to contemporary political campaigns (Issenberg 2012) regularly go under the microscope, as do the power of gaffes, mishaps and 'cut through' or unscripted moments, as well as the media portrayals of those events (e.g. Shorten 2004; Tiffen 2008). 
best small and fleeting, and campaign efforts by the major parties often neutralise one another. ${ }^{2}$ Many journalists and commentators have offered campaign-based explanations for the closeness of the 2016 Australian elections. For example, Labor's 'Mediscare' strategy late in the campaign is often invoked in explaining the narrowness of the Coalition's victory. Wayne Errington and Peter van Onselen make the unqualified assertion that ' $[\mathrm{u}]$ ndoubtably, Labor's disingenuous scare campaign resonated with the electorate' (2016: 180).

In this chapter we present an alternative view, closer to the scholarly consensus about campaign effects. We examine change in public opinion during the 44th Parliament, providing context for movement in voting intentions during the 2016 election campaign period. We also examine the quality of seat-specific polling ahead of the 2016 election.

We make four major findings:

1. Large movements in voter support occurred well before the formal campaign period, around events such as the September 2015 leadership spill that resulted in Malcolm Turnbull's ascension to the prime ministership and the 2014 Budget.

2. In the formal election campaign, there was relatively little movement in voting intentions, which was consistent with the major party campaigns neutralising each other. Contrary to popular narratives about the campaign, movements in voting intentions during the formal campaign period were smaller in magnitude than at other comparable periods during the 44th Parliament.

3. Polling organisations systematically overestimate Greens voting intentions, but underestimate Labor voting intentions. Two-party preferred voting intentions estimates were accurate when averaged across public polling. It would seem that a small, industry-wide underestimate of the Coalition vote was offset by the industry-wide overestimate of the Green vote, yielding an accurate estimate of the two-party preferred division of the vote.

4. Seat-specific polling underestimates Labor, but overestimates support for the Greens.

2 Reviews of the sizeable academic literature on campaign effects appear in Shanto Iyengar and Adam Simon (2000), D. Sunshine Hillygus (2010) and John Sides and Lynn Vavreck (2014). 
In general, seat-specific polls are subject to substantial biases, so much so that the typical seat-specific poll should be treated as if it had just one-sixth the nominal, stated sample size of the poll.

\section{Data and methodology}

The national-level polling data analysed here span the period between the 2013 and 2016 elections. The data collection includes virtually all polls in the public domain between the elections. ${ }^{3}$ Only polls with known fieldwork dates and known sample sizes are analysed. There are 399 national polls in this period with primary vote estimates and 400 polls with two-party preferred estimates. ${ }^{4}$ There are 10 de facto polling organisations responsible for the polls analysed (also see Goot, Chapter 5, this volume). Newspoll and Galaxy are treated as two separate polling organisations for the purposes of this analysis. ${ }^{5}$

Each poll is a snapshot of opinion, captured during a short temporal window. The precision of a poll is an increasing function of its sample size. For all but one day every three years (election day), the Australian public's voting intentions are not directly observed. The rest of the time, voting intentions are measured imperfectly through polls that change over time. In this chapter, we estimate the true state of public opinion underlying published polls with a statistical model (Jackman 2005, 2009). The model treats voting intentions as a hidden or latent state and uses what is visible - the published results of opinion polls — to recover the trajectory of voting intentions between the 2013 and 2016 federal elections.

By combining polls, the model increases the amount of information available for estimating latent public opinion, thus increasing the precision of the resulting estimates. By estimating and correcting for biases specific

3 We thank William Bowe for sharing data collected for Crikey, enabling data quality checks for missing data and data entry errors. We thank Murray Goot for graciously crosschecking our data collection with his own collection of polling data. Responsibility for the accuracy of the data remains our responsibility.

4 The difference between the two arises from an additional Morgan poll conducted immediately after the 2016 Budget, which published an estimate for the two-party preferred vote but did not publish primary voting intention estimates.

5 The contract that News Corp had with Cudex, a joint venture between News Corp and the British public relations firm WPP to conduct Newspoll-branded public-opinion polling research for the Australian, was transferred to Galaxy Research in July 2015 (Australian 2015). The Galaxy-run Newspoll adopts a mixture of robo-calling and online panel sampling techniques (Stirton 2015). 
to polling organisations ('house effects'), the model improves the estimate of latent voting intentions. We refer to bias not as favouritism, a partiality or prejudice for or against a political party, nor do we assert or imply any normative quality or the intention of any polling industry participant to change the content or appearance of their polling results (i.e. fabricate their research). Rather, we borrow from statistics our meaning of bias. ${ }^{6}$ In addition, the model has a dynamic component. This acknowledges the fact that voting intentions change over election campaigns and especially over the three-year term of a parliament. The model includes 'jumps' or discontinuities for events that can reasonably be expected to rapidly (if not instantaneously) move opinion. The model's estimates are further improved by anchoring voting intention estimates to the 2013 and 2016 election results; as on election days, voting intentions are not latent, but are directly observed.

Our model for poll results is

$y_{i} \sim \mathrm{N}\left(\xi_{t, i}+\delta_{j, i}, \sigma^{2}\right)$

where $y_{i}$ is a proportion, the estimate of a party's vote share in a published poll $i ; \xi_{t, i}$ is the true but latent level of support for the party on day $t$, the median date of field work; $\delta_{j, i}$ is the bias of polling organisation $j$, the polling organisation fielding poll $i$; and $\sigma^{2}$ is the variance of the error of poll $i$, a decreasing function of $n$, the known sample size of poll $i$. We set $\sigma^{2}=\left(y_{i} \times\left(1-y_{i}\right)\right) / n_{i}$. The normal distribution is justified by standard large sample arguments about the form of sampling error.

The dynamic component of the model is

$\xi_{t}-\mathrm{N}\left(\xi_{t-1}+\gamma_{k} D_{k, t}, \omega^{2}\right), \mathrm{t}=2, \ldots, \mathrm{T}$

where $t$ indexes the 1,038 days between the 2013 and 2016 elections (inclusive). The model is a random walk in which today's voting intentions $\xi_{t}$ will be equal to the previous day's voting intentions $\xi_{t-1}$ absent any polling information to the contrary (which enters the model via the first equation explained above). The $\gamma_{k}$ parameters are 'jumps', measuring the extent to which event $k$ disrupts the trajectory of voting intentions; $D_{k, t}$ is a binary indicator, set to one on the day that event $k$ occurs and zero otherwise.

6 The bias function of an estimator is the difference between an estimator's expected value and the true value of the parameter being estimated. If the difference between an estimate and the true value is zero, the estimates are called unbiased. Bias is an objective property of an estimator. 
The variance term $\omega^{2}$ measures the day-to-day variability or volatility of voting intentions. $\xi_{1}$ and $\xi_{T}$ are set to the 2013 and 2016 election results, respectively, for a given party. ${ }^{7}$ We specify two potential jump events: Turnbull's ascension to the prime ministership on 15 September 2015 and the prorogation of parliament on 21 March $2016 .{ }^{8}$

\section{Voting intentions 2013-16}

Before the 2016 formal election campaign there was considerable movement in voting intentions. Figures 6.1 and 6.2 summarise these movements for Labor, the Coalition and Green first preferences and for Coalition two-party preferred voting intentions. Large, electorally consequential movements in voting intentions occurred within months of the Abbott government coming to power, and following the September 2015 Liberal leadership spill.

There was a steady decline in Coalition primary voting intentions from the 2013 election result until the presentation of the 2014 Budget on 13 May. Before the 2014 Budget, the Coalition's primary vote fell below its poor showing in the 2007 landslide result (42.09 per cent) and did not recover until Turnbull took the leadership. This is in contrast to much commentary that cites the 2014 Budget for the Abbott government's woes (see e.g. Kirby 2014; Makinda 2015; Marston 2014; Ryan 2015). The Coalition's primary vote remained little changed save a few small fluctuations, seldom statistically significant.

After Turnbull became prime minister in September 2015, the Coalition's primary vote briefly moved well above its 2013 result ( 45.55 per cent). There was an immediate 5 per cent increase in the Coalition primary vote the day Turnbull became prime minister (see Figure 6.2); this

7 The normal distribution is chosen largely for convenience; other assumptions about the form of the day-to-day innovations might be plausible—for example, a heavy-tailed distribution such as the t-distribution. The 'jump' component of the model captures some of the more obvious sudden or abrupt changes in public opinion, such that the remaining innovations are probably well accommodated by the normal model assumed here. Alternative distributional forms for the day-today innovations are a topic for another paper.

8 Breaks were tested for the opening of parliament, the three federal budgets, the first sitting day of parliament following the summer recess, and the start of the 'Mediscare' campaign initiated with a television advertisement featuring former Labor PM Bob Hawke on 11 June (ALP 2016). There was little difference to the fit of the model and these additional break points were dropped from the model reported here. 
continued to improve until January. The Coalition's renewed popularity had a half-life of about four months - the 8 per cent gain in January from the leadership change dropped to a 4 per cent advantage by April. There was a net improvement ( 3 per cent) to the Coalition's vote from Tony Abbott's defenestration until the prorogation of parliament in March 2016. Or when viewed from the peak, there was a 5 per cent fall in Coalition voting intentions, from Christmas 2015 until the prorogation of parliament. Leadership changes have been quite frequent in recent Australian political history, with large boosts in a party's electoral standing in the polls followed by steady decline to the status quo ante or lower. The reasons for the rapid reversion in voting intentions after leadership changes are not well understood. ${ }^{9}$

The Labor primary vote had an immediate bounce following the 2013 election with another improvement shortly after the first parliamentary sitting in 2013. There was no significant bounce in Labor support from the 2014 Budget; Australian Labor Party (ALP) vote intentions remained unchanged from their position in December 2013. When Turnbull replaced Abbott, there was an immediate 3.8 per cent fall in Labor voting intentions (see Figure 6.2), followed by a further 2 per cent decline in the next two months. From January until the prorogation, Labor gained 4 per cent more vote share, the inverse of the Coalition's loss.

The Greens' primary vote moved reasonably slowly over the life of the parliament. The Greens won 8.65 per cent of House of Representatives first preferences in 2013. Our analysis suggests a slow improvement in the Greens' electoral position over 2014, but especially over 2015-noting that Richard Di Natale became the Greens leader on 6 May 2015. By the time of the Turnbull ascension, we estimate the Greens had 12 per cent of first preferences or nearly a 50 per cent improvement on their 2013 result. After Turnbull became prime minister, Green support fell by about 1 per cent (see Figure 6.2) with roughly another 1 per cent ebbing away through 2016 to the 10.23 per cent Greens first preference result recorded at the 2 July election.

9 We agree that an update to the literature on leadership effects on Australian public opinion is probably warranted (McAllister 2003; Kefford 2013). 

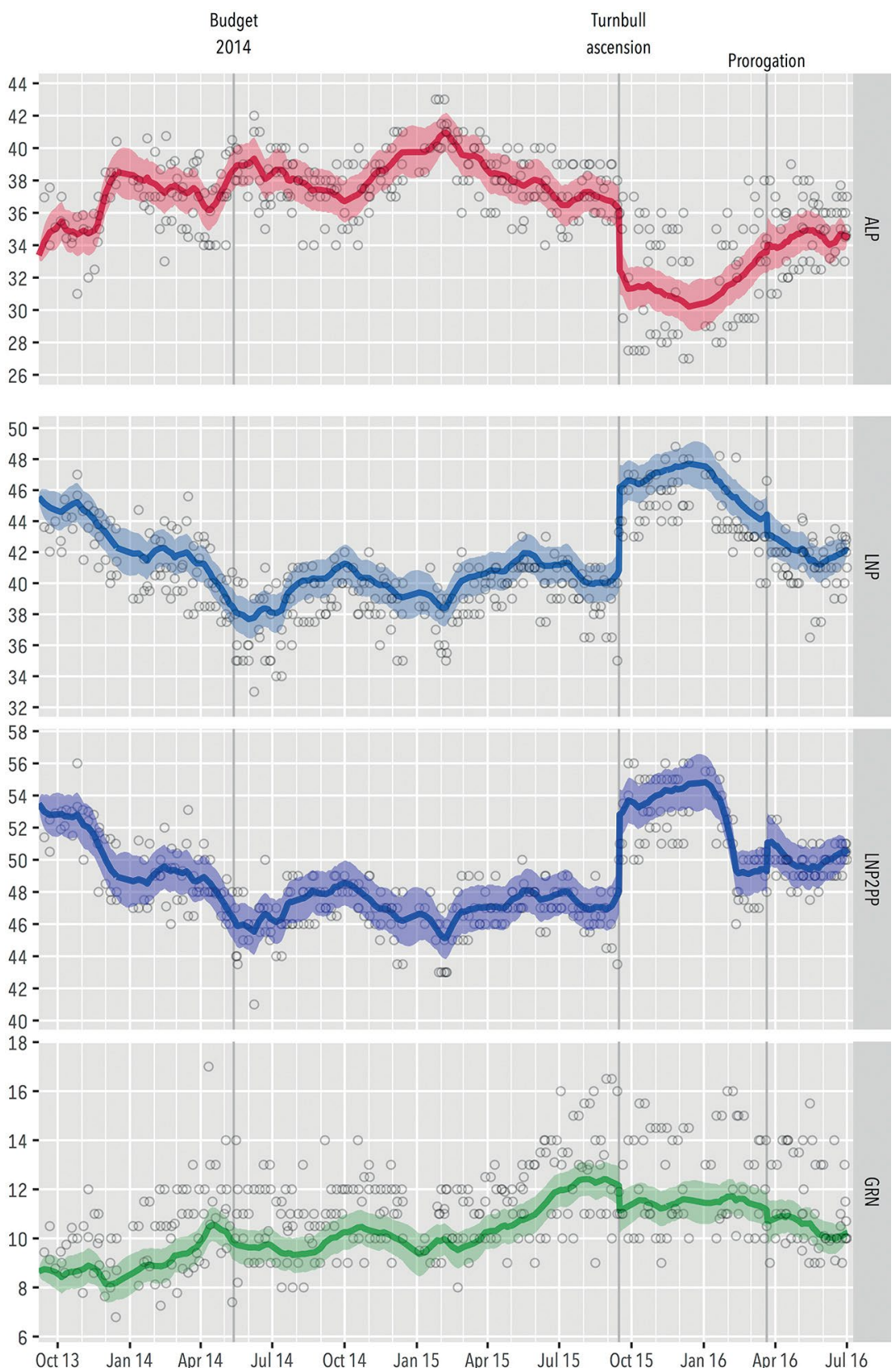

Figure 6.1. Trajectories of support for various parties (voting intentions, per cent), 2013-16

Note. Shaded regions indicate 95 per cent credible intervals, open circles indicate polls. Source. ( $)$ Simon Jackman and Luke Mansillo collated these data over the course of the campaign, and created the figure from the estimates produced from their model. 
As seen in Figure 6.1, changes in the Coalition's two-party preferred vote reflect changes in its primary vote, but there are some differences. The Coalition shed 4 per cent of its two-party preferred vote between the 2013 election and the end of year, more than 1 per cent per month. The Coalition's two-party preferred result remained at 49 per cent until April 2014. A further 3 per cent was lost in April 2014 in the lead-up to the 2014 Budget. From June 2014 to September 2015, there was relative stability in two-party preferred voting intentions until Turnbull became prime minister in September 2015. The Coalition two-party preferred figures peaked at almost 55 per cent in the 2015-16 Christmas/New Year period, but fell dramatically (to 50 per cent) as the 2016 parliamentary sittings commenced.

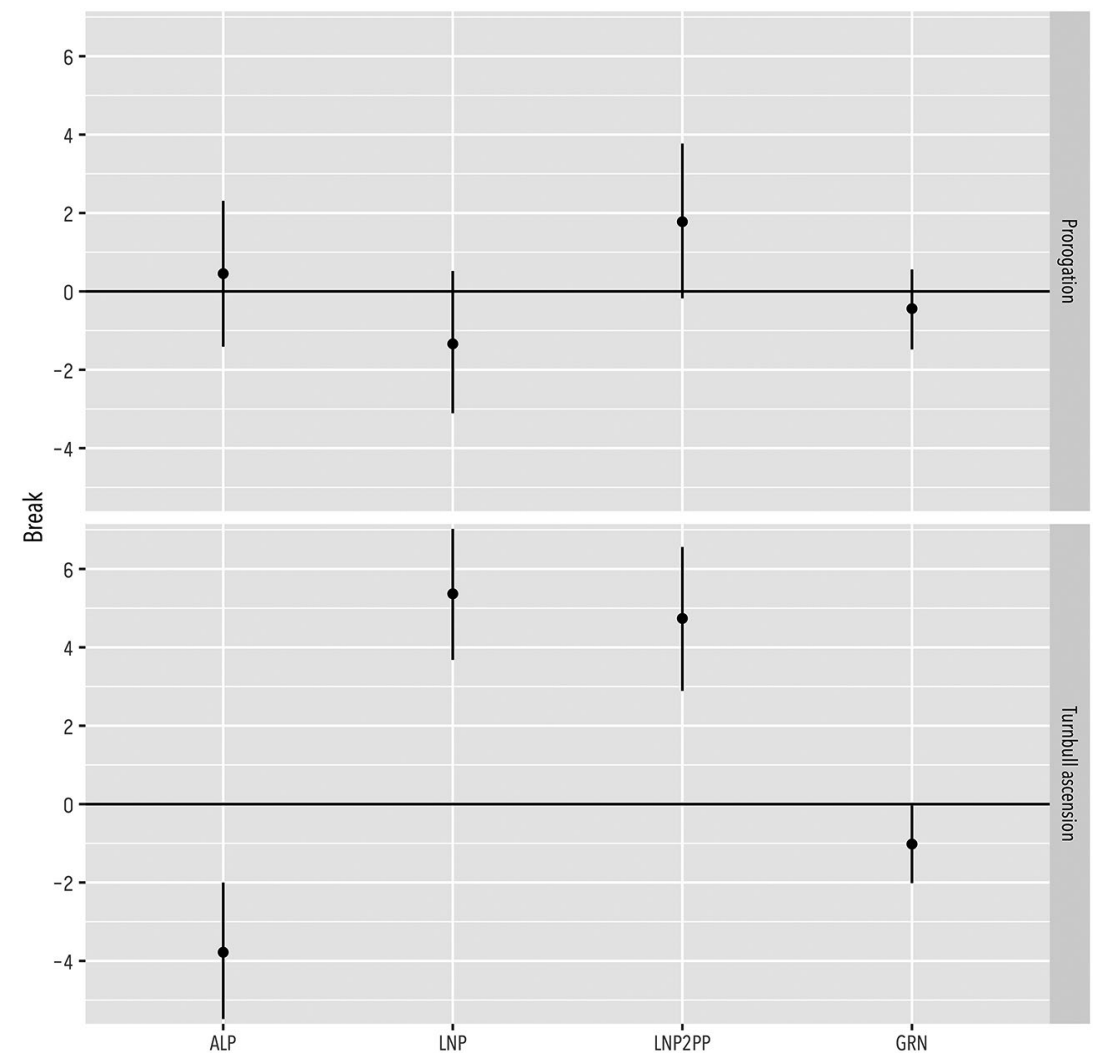

Figure 6.2. Jumps in voting intentions associated with the prorogation of parliament and Turnbull ascension

Note. Vertical lines span 95 per cent credible intervals.

Source. ( S Simon Jackman and Luke Mansillo collated these data over the course of the campaign, and created the figure from the estimates produced from their model. 


\section{Two campaign myths: 'Mediscare' and the 'Green slide'}

We find relatively little movement in voting intentions during the formal campaign period (see Figure 6.3), a point noted by some commentators during the campaign itself (e.g. Hartcher 2016). We define the de facto start of the 2016 election campaign with the proroguing of parliament on 21 March, well ahead of the Budget delivered on 3 May and the issue of writs on 9 May. The public opinion movements we find in the campaign are small in contrast to the previous 31 months.

The closeness of the election was widely attributed to Labor's 'Mediscare' campaign (see e.g. Errington and van Onselen 2016; Gillespie 2016; Williams 2016). We find this to be questionable given the available evidence (see Elliot and Manwaring, Chapter 24, this volume). At prorogation, the Coalition primary vote was 43 per cent. This had fallen to 41 per cent a month out from polling day. The precipitous decline from January was arrested by early June (see Figure 6.3). In the last month of the campaign, it seems that the Coalition primary vote had an almost 1 per cent recovery, but this level of change is too small to be confidently detected by the available data and our model. The most we can say is that there appeared to be very little movement in Coalition primary voting intentions compared to the period before the campaign.

The 'Mediscare' campaign began in earnest with advertisements featuring Bob Hawke first appearing on 11 June. In Errington and van Onselen's (2016: 154) assessment, '[t]he Mediscare attack was designed not just to appeal more to swinging voters (as well as galvanising Labor voters) but to show that Shorten was playing to win', and that a 'pathway to victory' was possibly indicated by 'Labor's tracking polling and focusgroup research [which] had picked up an unusual high concern with health funding.' Errington and van Onselen (ibid.) assert that 'Labor had tapped into a rich vein of distrust voters had with the government- the trick would be exploiting it to maximum effect'. But once the 'Mediscare' campaign was rolled out, the Coalition primary vote did not deteriorateand even improved thereafter-suggesting the 'Mediscare' campaign was nowhere near as powerful as many accounts have asserted. ${ }^{10}$

10 For a more detailed discussion, see Elliot and Manwaring, Chapter 24, this volume. 
DOUBLE DISILLUSION
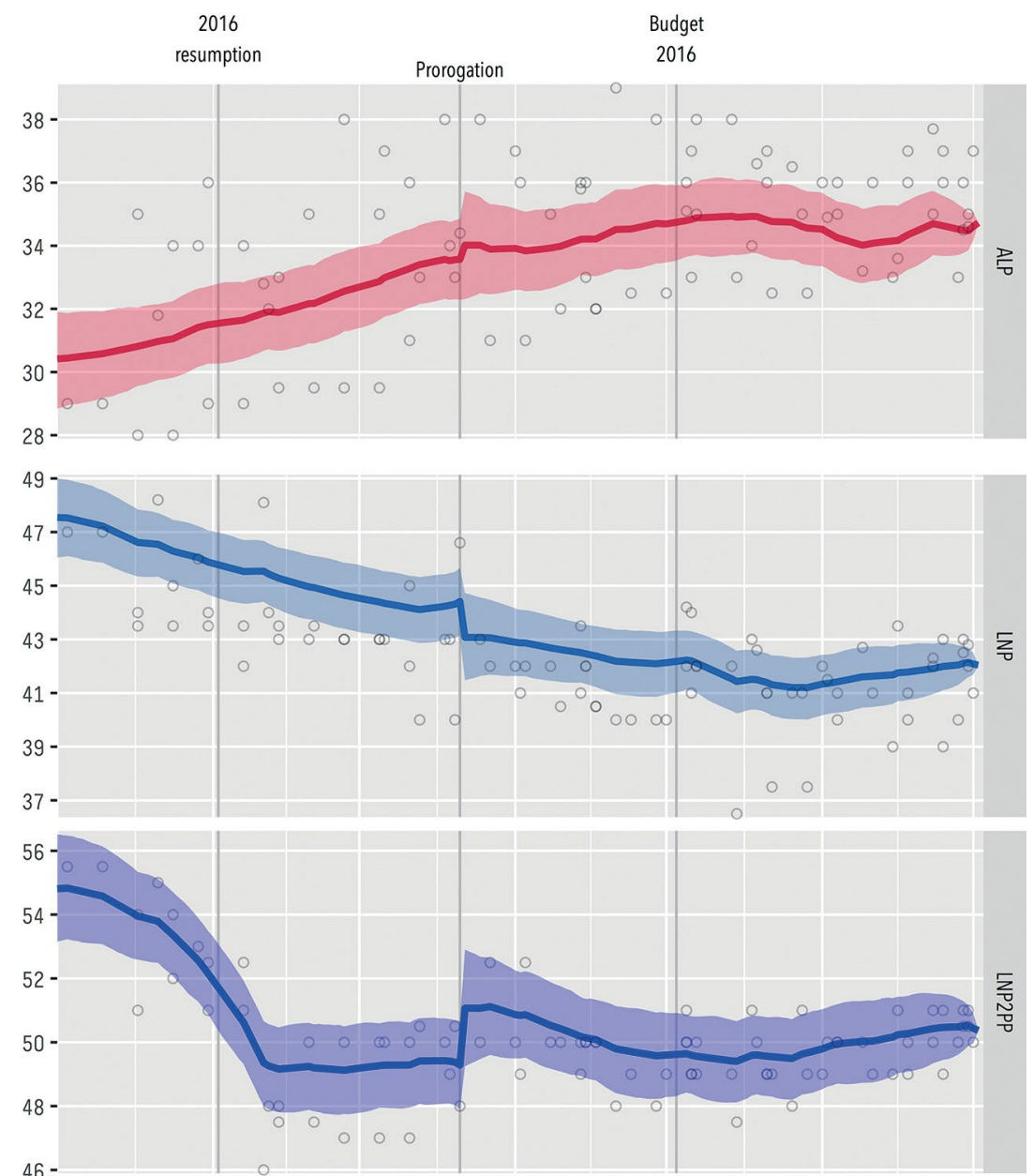

46

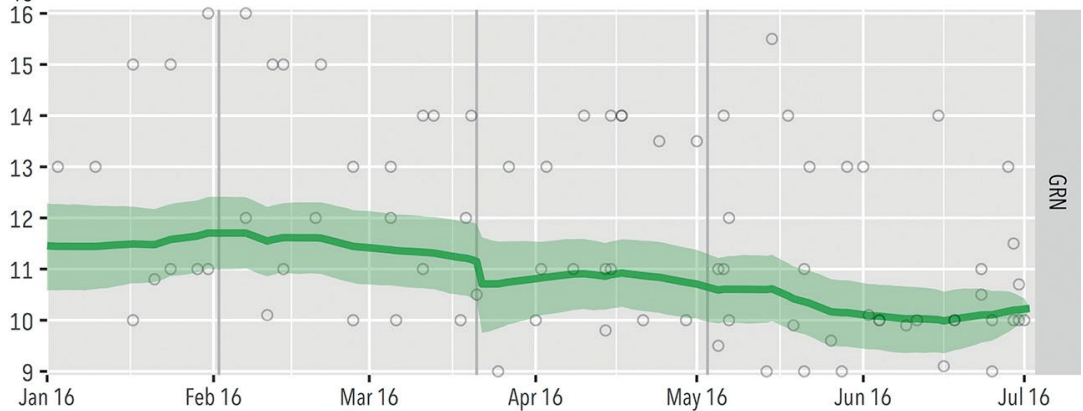

Figure 6.3. Trajectories of support for various parties (voting intentions, per cent), restricted to calendar year 2016

Note. Shaded regions indicate 95 per cent credible intervals, open circles indicate polls.

Source. ( ) Simon Jackman and Luke Mansillo collated these data over the course of the campaign, and created the figure from the estimates produced from their model. 
This said, Labor too appears to have had a 1 per cent improvement in its primary vote over the campaign period, between the prorogation in March and the 2 July election. Labor lost vote share over the period post-budget to early June-around 1 per cent-but appears to have regained it by election day. But much like the Coalition primary vote, the Labor vote remained stable for the campaign relative to the recent parliamentary period. Again, there is little evidence that the 'Mediscare' campaign had a significant impact on public opinion. As Figure 6.3 makes clear, the larger and more consequential movement in Labor's primary vote shareand the Coalition's vote share, too-occurred between Christmas 2015 and the start of the formal campaign. Labor's first preference vote share improved from 30 per cent to 35 per cent in the first five months of 2016, and meandered around that level through the formal campaign period. From when parliament was prorogued until the Budget, the Greens averaged 11 per cent of first preferences; this fell by 1 per cent after the Budget. Once the writs for the 2016 election were issued the Greens and several commentators were bullish on the Greens' prospects (Chang 2016; Evershed et al. 2016; see also Jackson, Chapter 13, this volume). However, we find that the Greens vote share continued to decline or at best was stagnant. The Coalition's two-party preferred vote was highly stable for the campaign, much like its primary vote. This was in contrast to movements throughout the parliamentary period. The 1 per cent gain Labor made in the month after the writs were issued was lost in the last month of the campaign.

\section{Polling organisation bias}

Figure 6.4 summarises the biases or 'house effects' for each polling organisation, for Coalition, Labor and Greens primary and Coalition two-party preferred voting intentions. Vertical lines indicate the range of 95 per cent credible intervals around each bias estimate. A given house effect estimate can be interpreted as being indistinguishable from zero at conventional levels of statistical significance, if the 95 per cent credible interval overlaps zero. The house effect labelled 'Average' is the average of the house effects; in effect, this average house effect enables us to show the extent to which the polling industry displayed a collective bias. 


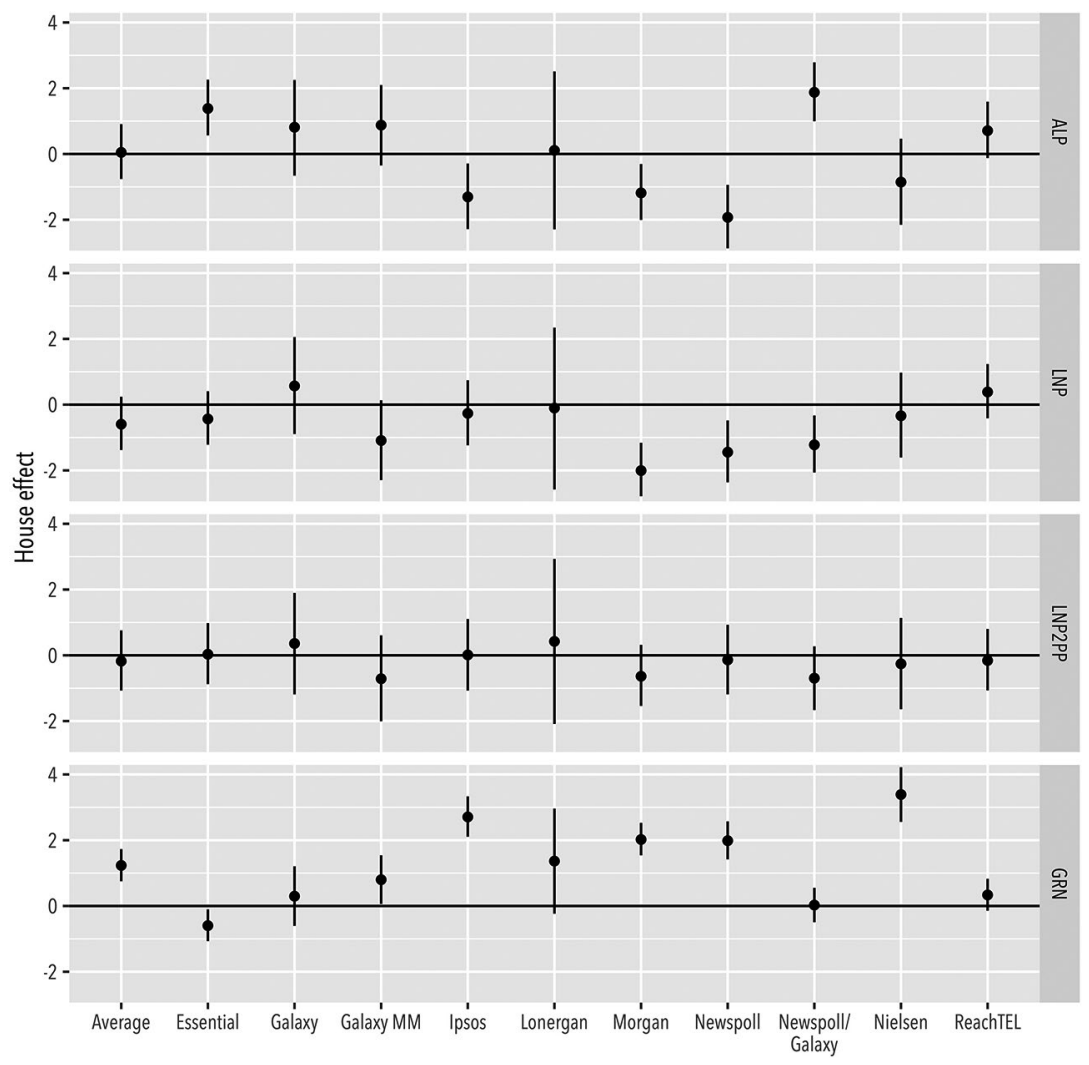

Figure 6.4. Polling organisation bias estimates

Note. Vertical lines span 95 per cent credible intervals. The house effect labelled 'Average' is the average of the house effects; in effect, this average house effect assesses whether the polling industry displayed a collective bias.

Source. (C) Simon Jackman and Luke Mansillo collated these data over the course of the campaign, and created the figure from the estimates produced from their model.

For Coalition primary vote estimates, three of the 10 polling organisations had a statistically significant bias. Morgan and both Newspoll regimes underestimated Coalition primary voting intentions. Morgan underestimated the Coalition primary vote more than either Newspoll regime. Five of the 10 polling organisations analysed showed a significant Labor bias in their estimates of the primary vote. Essential and Newspoll, since July 2015, overestimated Labor primary voting intentions, whereas Ipsos, Morgan and Newspoll until June 2015 significantly underestimated 
Labor primary voting intentions. ${ }^{11}$ Changes to the Australian's public opinion research sourcing also changed its underlying methodological procedures. This has implications for Labor primary vote estimates. The old Newspoll underestimated the Labor primary vote by 1.9 per cent, but after the polling organisation changed, the new Newspoll overestimated it by 1.9 per cent; the difference being 3.8 per cent.

In July 2015, political editors and commentators were quick to remark on the shift in Newspoll. Fairfax Media's chief political correspondent Mark Kenny noted, 'primary support for the ALP [was] a relatively healthy 39 per cent, up from 37 per cent a fortnight ago and 5 per cent up from its 34 per cent in mid-June' (Kenny 2015). While the polls present much fodder for journalists to discuss, they appear not to have been terribly mindful of potential poll bias shifts. Averaged over the polling organisations used here, there is no 'industry-wide', collective bias in polling for Labor first preferences or Coalition two-party preferred estimates. There is a small underestimate of Coalition first preferences (about 0.6 per cent), but this estimate is not distinguishable from zero at conventional levels of statistical significance.

Then again, there is an unambiguous tendency for the polling industry to have overestimated Greens first preferences. Four of the 10 polling organisations significantly overestimated the Greens' primary vote: Ipsos, Morgan, Nielsen and Newspoll before July 2015. Essential underestimates the Greens' primary vote, but this is to a much lesser extent than other polling organisations overestimate Greens voting intentions. The industry, on average, overestimated the Greens support by more than 1 per cent. Overestimates of the Greens primary vote have also been observed in New Zealand (Wright, Farrar and Russell 2013). There could be a few reasons for the large Greens primary vote overestimation observed. Some likely causes include incorrect weighting of younger respondents, voter confusion between House of Representatives and Senate voting, survey design issues (question wording and response options), and respondents-who expressed an intention to vote for the Greens-being less likely to turn out.

No significant house biases for national Coalition two-party preferred voting intentions were observed. In this respect, polling organisations performed well. It appears that a small, collective underestimate of the

11 From July 2014, Nielsen ceased Australian public opinion research operations on voting intentions (Mitchell 2014). Fairfax Media has since sourced its public opinion polling from Ipsos Australia. 
Coalition vote was offset by the collective overestimate of the Green vote, yielding an unbiased estimate of the two-party preferred division of the vote.

\section{Seat-specific polling}

We collected estimates of first preference voting intentions from 88 seatspecific polls that were conducted in 48 electoral divisions from January 2016 until election day. These electoral divisions were typically more marginal than the average seat. Sample sizes for these polls ranged from 500 to 1,600 , with an average of 626 . The sample sizes for these polls are smaller than those in national polls (an average of 1,498 respondents). To measure the error for seat-specific polling, we compared poll estimates to the election results in the corresponding seat. Figure 6.5 displays these comparisons. The orange line is a 45-degree line; all data points would lie on this line if poll results perfectly predicted the election results. The blue line is a regression line, summarising the relationship between poll estimates and actual results.

Table 6.1 presents summaries of the poll errors. Averaged across seats, seat-specific polls overestimated the Greens vote by 0.7 per cent and the Coalition vote by 0.6 per cent, and underestimated the Labor vote by 2.2 per cent and Xenophon candidates by just 0.25 per cent. The bias with respect to Labor vote shares is especially pronounced, with underestimates of Labor's showing in seats like Macarthur (New South Wales (NSW)) and Franklin (Tasmania (TAS)) larger than 10 per cent. The median absolute error (ignoring whether the poll error is an overestimate or an underestimate) is actually slightly larger for the Coalition than for Labor ( 3.5 per cent versus 3.28 per cent), but both errors are reasonably large. The root mean square error (RMSE) is largest for Labor-on the order of 5 per cent—and 4.3 per cent for the Coalition. This is considerably larger than the RMSE we ought to see from polls with a sample size of roughly 600 respondents. ${ }^{12}$ The poll errors for the Greens and Xenophon candidates are smaller in magnitude than those for Labor and the Coalition because the magnitudes involved are smaller quantities (e.g. the median Green vote share in the seats covered by these polls is 8 per cent).

12 Unbiased polls with a sample size of 626 respondents trying to estimate a (known) target of 50 per cent will have a root mean square error of $\sqrt{(.5 \times .5) / 626} \approx .02$ or 2 per cent. 

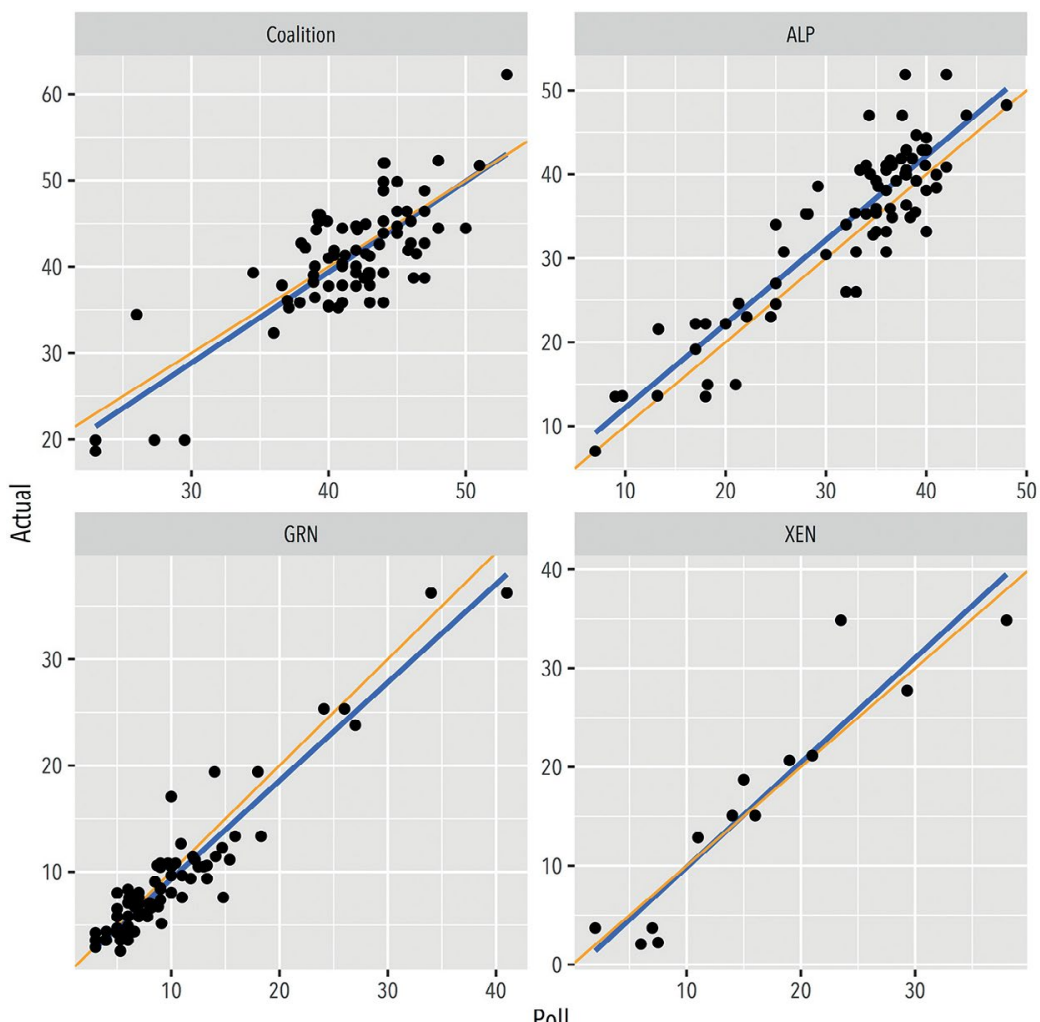

Figure 6.5. Performance of seat-specific polls

Source. (c) Simon Jackman and Luke Mansillo collated these data over the course of the campaign, and created the figure from the estimates produced from their model.

\section{Table 6.1. Summary of poll errors}

\begin{tabular}{|l|c|c|c|c|}
\hline & Coalition & ALP & Green & Xenophon \\
\hline Average & -0.58 & 2.19 & -0.68 & 0.25 \\
\hline Median absolute & 3.50 & 3.28 & 1.42 & 1.69 \\
\hline RMSE & 4.32 & 4.99 & 2.27 & 3.83 \\
\hline Effective $n$ & 129.91 & 92.14 & 142.89 & 95.49 \\
\hline Coverage rate & 57.50 & 53.16 & 78.21 & 60.00 \\
\hline Number of polls & 80 & 79 & 78 & 15 \\
\hline Number of seats & 46 & 45 & 44 & 10 \\
\hline
\end{tabular}

Note. Effective $\mathrm{n}$ is the sample size of a simple random sample that generates the corresponding level of root mean square error (RMSE). The coverage rate is the percentage of times that a 95 per cent confidence interval for each poll estimate includes the corresponding outcome.

Source. (C) Simon Jackman and Luke Mansillo collated these data over the course of the campaign, and created the figure from the estimates produced from their analysis. 
Indeed, it is possible to invert the formula for RMSE to recover the effective sample size of the seat-specific polls, generating an estimate of the quality of information in these polls. ${ }^{13}$ The total survey error between the poll's predicted result and the observed result is expressed in the same terms as total sampling error. For polls estimating Coalition and Labor vote shares, the effective sample size is around 100, far below the 626 average sample size in these polls; an indication of the unreliability of seat-specific polls. Seat-specific polls are subject to substantial biases, so much so that they contain as much information as an unbiased sample of just one-sixth the nominal sample size of the poll.

Similarly, we report the coverage rate of the poll estimates in Figure 6.5, the proportion of times that 95 per cent confidence intervals formed around each poll estimate actually lie within the observed election result. ${ }^{14}$ This, too, is a useful measure of the performance of the polls. Unbiased polls that utilise simple random sampling ought to have coverage rates equal to their nominal coverage rates given by statistical theory. This means, using 95 per cent confidence intervals, the election results should fall within the 95 per cent confidence interval bounds on 95 per cent of occasions. Table 6.1 shows poor coverage rates for estimates of Coalition, Labor and Xenophon support: just 58 per cent, 53 per cent and 60 per cent, respectively. Poll estimates of Green support in specific seats fare a little better, with a coverage rate of 78 per cent.

Figure 6.6 disaggregates poll errors (measured as absolute values) by pollster and by party. There were some impressive misses. The bulk of polls were produced by ReachTEL, Newspoll and Galaxy, which had median absolute errors (MAE) of 3.5 per cent, 4.3 per cent and 2.6 per cent respectively in their seat-specific estimates of Coalition support. The pollster with the greatest Coalition MAE was MediaReach, with just one poll in Solomon (Northern Territory (NT)), which had an error of 8.4 per cent. This large error — and many others not so large-are well beyond what we might reasonably expect from random sampling with the sample sizes reported here. ${ }^{15}$ Patently, other sources of survey error are at work,

13 We do this by rearranging the formula RMSE $=\sqrt{(p \times(1-p)) / n}$, setting $p$ equal to the median outcome for a given party over the seats covered by those polls, then solving for $n$.

14 In computing the coverage rate, we form a 95 per cent confidence interval around the published poll result via a normal approximation to the sampling distribution of each poll result, setting the upper and lower limits of the confidence interval to $\pm 1.96 \hat{\sigma}$, where $\hat{\sigma}=\sqrt{(\hat{p} \times(1-\hat{p})) / n}$, where $p$ is the poll result expressed as a proportion and $n$ is the published sample size of the poll.

15 Recall that in footnote 12 we computed the standard error for a poll-based estimate of a proportion of 0.5 with a random sample of 626 (the average sample size of the seat-specific polls we analyse). The expected median absolute error from unbiased polls with this sample size is 1.34 per cent. 
including frame errors (the sampling frame is not representative of the electorate), non-response bias (the set of respondents taking the survey are not representative of the electorate, even after corrections such as weighting), or errors in weighting.

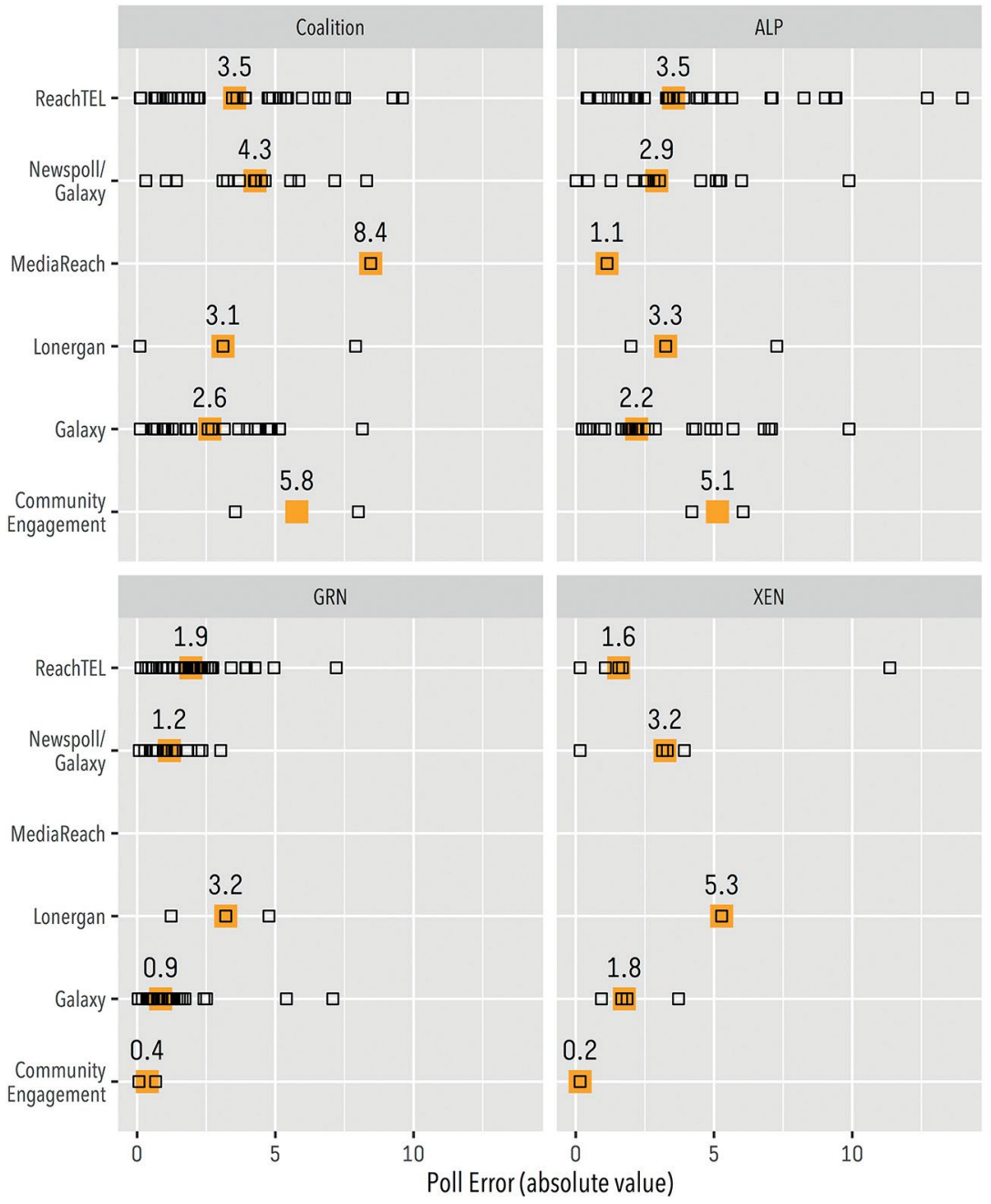

Figure 6.6. Performance of seat-specific polls by party and pollster

Note. Polling errors (absolute values) of estimates distance from the actual election result are plotted, by party and pollster. The orange point marks the median absolute error for a pollster when estimating the indicated party's level of support in an electoral division.

Source. ( ) Simon Jackman and Luke Mansillo collated these data over the course of the campaign, and created the figure from the estimates produced from their analysis. 
Errors in seat-specific ALP polling were similar to Coalition polling errors. The best-performing pollster was MediaReach, with their one poll in Solomon (NT), reporting Labor first preferences of 42 per cent (actual 40.87 per cent). Galaxy had an MAE of 2.2 per cent, the lowest error rate of pollsters that regularly fielded during the campaign. Newspoll did not perform much worse with an MAE of 2.9 per cent. The 3.5 per cent ALP ReachTEL MAE and large distribution underscores the variability in quality of seat-specific polling. Greens seat-specific polling produced errors that are generally smaller than those for the major parties but, as noted earlier, this largely stems from the fact that Greens vote shares (both estimated and actual) are so much smaller than those for the major parties. In relative terms, the Green errors are actually much larger. The MAE of seat-specific poll estimates of Labor's support was 3.28 per cent (see Table 6.1); Labor's median vote share across the seats in which we have poll estimates was 35.55 per cent, implying that the MAE is about 9.2 per cent of Labor's median vote share. The Green MAE is 1.42 on a median vote share of just 8.04 per cent, implying that the MAE is 17.7 per cent of the Greens' median vote share, almost double the relative size of Labor's polling error.

A plausible hypothesis is that seat-specific polling fares better when conducted close to election day, and that errors in the polls might be larger when conducted weeks or months earlier, before the campaign has firmed up voters' decisions. We explore this hypothesis with the analysis shown in Figure 6.7, plotting the magnitude of seat-specific poll errors by the field date of the poll. With the exception of seat-specific poll estimates of Labor vote share, there is little evidence that the accuracy of seat-specific polling improved as the election grew closer. The trend lines in Figure 6.7 are horizontal for both Coalition and Green seat-specific polling, and statistically indistinguishable from a horizontal or 'no change' trend for the relatively small number of polls assessing seat-level support for Xenophon candidates. For Labor seat-by-seat outcomes, exceptionally large polling errors (e.g. greater than 10 per cent in magnitude) are concentrated in polls conducted more than six weeks before the election, although poll errors as large as 10 per cent were recorded in polls fielded less than two weeks prior to the election; Macarthur (NSW) was the source of the largest error in ALP seat polling (a 14 per cent miss by a ReachTEL poll on 19 May) and it also supplied 10 per cent misses for Galaxy (twice, 11 May and 22 June) and Newspoll/Galaxy (14 June), underestimating ALP's 51.9 per cent result in every case. Three seat-specific polls fielded very close to 
the election-on 29 and 30 June in Adelaide (South Australian (SA)) by Galaxy, Chisholm (Victoria (VIC)) by ReachTEL and in Port Adelaide (SA) by Galaxy - performed very well with respect to Labor vote share, with errors of less than 1 per cent in each case. The same polls missed Coalition vote shares by magnitudes of 2.6 per cent, 5.4 per cent and 4.4 per cent respectively, but performed relatively well with respect to the Greens, with errors with magnitudes of 1.4, 2.4 and 0 per cent (to one decimal place).

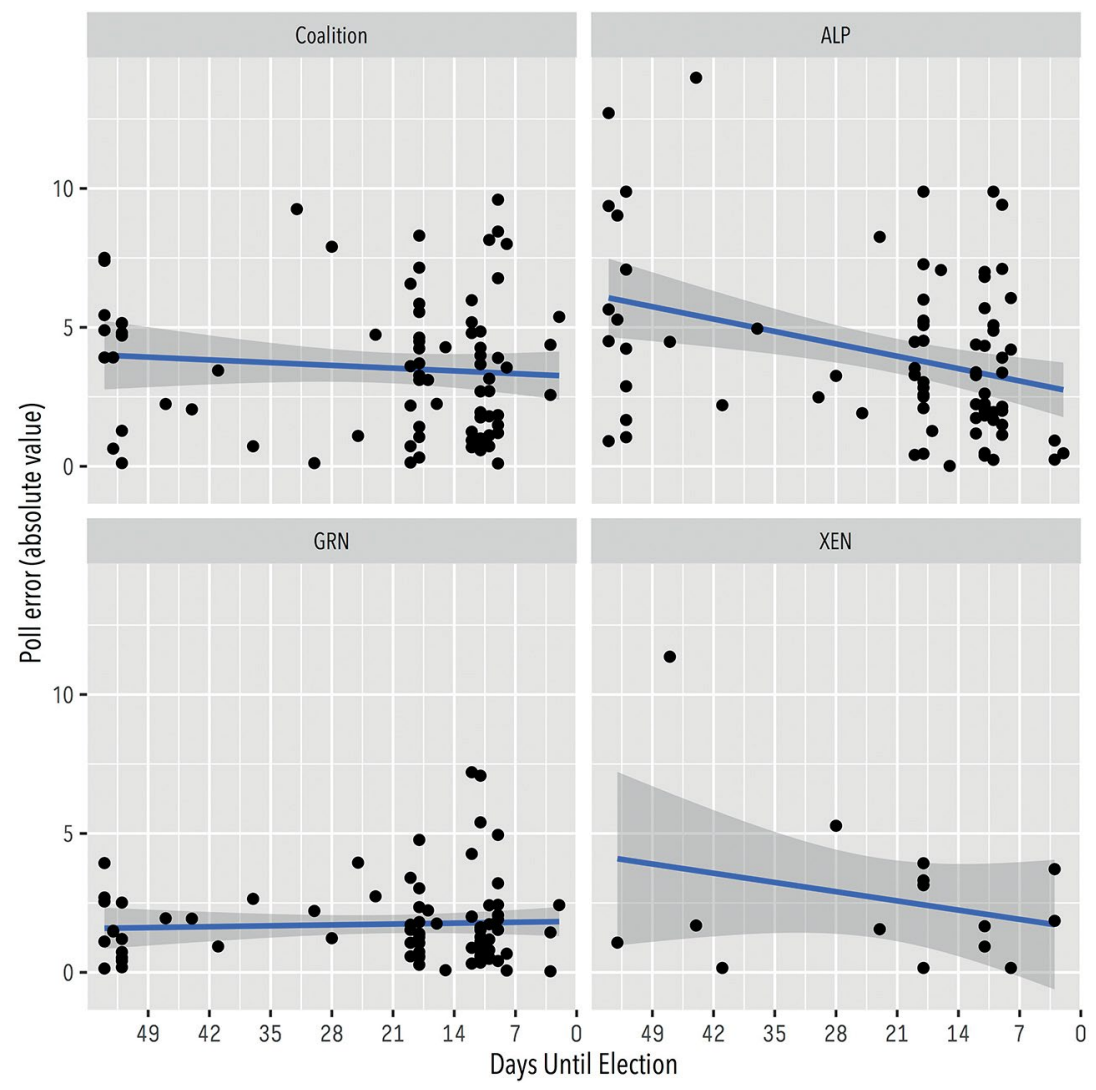

Figure 6.7. Performance of seat-specific polls, by party and over time (days until election)

Note. Each plotted point is the error (absolute value) of a separate poll. The blue line summarises the time trend of the absolute errors.

Source. @ Simon Jackman and Luke Mansillo collated these data over the course of the campaign, and created the figure from the estimates produced from their analysis. 
All of this evidence suggests interpreting seat-specific polling with great caution. Labor support was systematically underestimated across the polling industry and across seats. Stated confidence intervals for seatspecific estimates are far too small, or, equivalently, the actual statistical power of the polls is far less than the nominal confidence intervals and 'margins of error' accompanying media reports of the polls themselves. Published confidence intervals and 'margins of error' should be inflated by a factor of 240 per cent for estimates of Coalition support, by 270 per cent for estimates of Labor support and by 185 per cent for estimates of Green support. These are extremely large inflation factors; for instance, a seatspecific poll estimating Labor support that claims to have a margin of error of \pm 3 per cent ought to be considered as having a confidence interval of \pm 8.1 per cent.

\section{Summary}

The 44th Australian Federal Parliament experienced considerable volatility in voting intentions. Turnbull's ascension produced the largest change in voting intentions in the three-year period between the 2013 and 2016 elections. The 5 per cent fall in Coalition support from Christmas 2015 until prorogation would suggest that Turnbull went to the 2016 election too late. These large movements stand in stark contrast to small, statistically negligible movements in voter sentiment during the campaign period. Since we find very little movement in voting intentions during the formal campaign, it would seem that media narratives about the power of campaign events are best considered with a grain of salt. For instance, it is simply not the case that Labor's 'Mediscare' campaign undermined the Coalition's electoral position. The evidence available to us indicates that public opinion was stable over the campaign.

We also make several conclusions about the quality of polls. Poll estimates of the two-party preferred vote were generally of high quality. No survey house displays statistically significant bias in their two-party preferred estimates. Estimates of national, first preference vote shares were also largely accurate. Morgan and Newspoll underestimated the Coalition's first preference vote share by between 1.1 per cent and 1.9 per cent. Essential and Newspoll overestimate the Labor primary between 0.8 per cent and 1.2 per cent, while the active polling organisations Ipsos and Morgan estimated their primary vote between 1.8 per cent and 
1.9 per cent. Greens primary vote estimation contained more bias, with overestimations that range between 1.9 per cent and 2.6 per cent across polling organisations.

We find seat-specific polling to be highly unreliable. These polls systematically underestimate the Labor vote and overestimate the Greens vote. The bias in the average seat-specific poll is so great that these polls should be cautiously treated since they have an effective sample size a sixth of that fielded. This is in marked contrast to the performance of national polling, indicating that reliably generating high-quality samples of small areas (Commonwealth electoral divisions) is a challenging task for almost all of the polling organisations we considered here.

\section{References}

Australian. 2015. 'Newspoll changes polling partner to Galaxy Research'. Australian, 5 May, 4.

Australian Labor Party (ALP). 2016. 'Bob Hawke speaks out for Medicare, do you?' YouTube, 11 June. Available at: youtube.com/ watch?v=pZ9EfrpPcQs

Chang, Charis. 2016. 'The Greens could be "quite powerful" in next parliament'. news.com.au, 12 May. Available at: www.news.com.au/ national/federal-election/the-greens-could-be-quite-powerful-in-nextparliament/news-story/d2c95f8eb948279c40f74074017d9639

Errington, Wayne and Peter van Onselen. 2016. The Turnbull Gamble. Melbourne: Melbourne University Publishing.

Evershed, Nick, Bridie Jabour, Michael Safi and Miles Martignoni. 2016. 'How to understand the numbers flying around election 2016-Behind the Lines Podcast'. Guardian, 12 May. Available at: www.theguardian. com/australia-news/datablog/audio/2016/may/12/behind-the-lineshow-to-understand-the-numbers-flying-around-election-2016

Gillespie, Jim. 2016. 'Labor's "Mediscare" campaign capitalised on Coalition history of hostility towards Medicare'. The Conversation, 5 July. Available at: theconversation.com/labors-mediscare-campaigncapitalised-on-coalition-history-of-hostility-towards-medicare-61976 
Halperin, Mark and John Heilemann. 2010. Game Change: Obama and the Clintons, McCain and Palin, and the Race of a Lifetime. New York: HarperCollins.

Hartcher, Peter. 2016. 'Federal election 2016: It's 50-50, so what was the point of it all?' Sydney Morning Herald, 1 July. Available at: www.smh. com.au/federal-politics/federal-election-2016/federal-election-2016its-5050-so-what-was-the-point-of-it-all-20160630-gpvuzj.html

Hillygus, D. Sunshine. 2010. 'Campaign effects on vote choice'. In Jan E. Leighley (ed.), Oxford Handbook of American Elections and Political Behavior. Oxford: Oxford University Press, pp. 326-45.

Issenberg, Sasha. 2012. The Victory Lab. New York: Broadway Books.

Iyengar, Shanto and Adam F. Simon. 2000. 'New perspectives and evidence on political communication and campaign effects'. Annual Review of Psychology 51: 149-69. doi.org/10.1146/annurev.psych.51.1.149

Jackman, Simon. 2005. 'Pooling the polls over an election campaign'. Australian Journal of Political Science 40(4): 499-517. doi.org/ 10.1080/10361140500302472

- 2009. Bayesian analysis for the social sciences. Hoboken, NJ: John Wiley \& Sons. doi.org/10.1002/9780470686621

Kefford, Glenn. 2013. 'The presidentialisation of Australian politics? Kevin Rudd's leadership of the Australian Labor Party'. Australian Journal of Political Science 48(2): 135-46. doi.org/10.1080/1036114 6.2013 .786676

Kenny, Mark. 2015. 'Bill Shorten to unveil 50\% renewable energy target at Labor conference'. Sydney Morning Herald, 22 July. (Original title: 'Shorten to propose bold new climate goal'). Available at: www. smh.com.au/federal-politics/political-news/bill-shorten-to-unveil50-renewable-energy-target-at-labor-conference-20150721-gih4bp. $\mathrm{html} \%$

Kirby, Tony. 2014. 'Health and science suffer major cuts in Australia's budget'. The Lancet 383: 1874-76. doi.org/10.1016/S0140-6736 (14)60901-6 
Makinda, Samuel. 2015. 'Between Jakarta and Geneva: Why Abbott needs to view Africa as a great opportunity'. Australian Journal of International Affairs 69(1): 53-68. doi.org/10.1080/10357718.20 14.950629

Marston, Greg. 2014. 'Welfare for some, illfare for others: The social policy agenda of the Abbott Government'. Australian Review of Public Affairs, October. Available at: www.australianreview.net/digest/ 2014/10/marston.html

McAllister, Ian. 2003. 'Prime ministers, opposition leaders and government popularity in Australia'. Australian Journal of Political Science 38(2): 259-77. doi.org/10.1080/1036114032000092710

Mitchell, Jake. 2014. 'Nielsen ends 40 years of public polling'. Sydney Morning Herald, 2 June. Available at: www.smh.com.au/business/ media-and-marketing/nielsen-ends-40-years-of-public-polling20140602-39djv.html

Ryan, Matthew. 2015. 'Contesting "actually existing” neoliberalism'. The Journal of Australian Political Economy 76: 79-102.

Shorten, Bill. 2004. After the Deluge? Rebuilding Labor and a Progressive Movement. Fitzroy, Victoria: Arena Printing and Publishing Pty Ltd.

Sides, John and Lynn Vavreck. 2014. The Gamble: Choice and Chance in the 2012 Presidential Election. Princeton, NJ: Princeton University Press. doi.org/10.1515/9781400852277

Stirton, John. 2015. 'New Galaxy "Newspoll" to rely on robopolling and online data'. Sydney Morning Herald, 9 May. Available at: www.smh. com.au/national/new-galaxy-newspoll-to-rely-on-robopolling-andonline-data-20150508-ggx48a

Tiffen, Rodney. 2008. 'Campaign tactics, media bias and the politics of explanations: Accounting for the Coalition's loss in 2007'. Communication, Politics \& Culture 41(2): 8-29.

Williams, Pamela. 1997. The Victory: The Inside Story of the Takeover of Australia. Sydney: Allen \& Unwin. 
— 2016. 'Federal election 2016: How Labor's Mediscare plot was hatched'. Weekend Australian, 4 July. Available at: www.theaustralian. com.au/federal-election-2016/federal-election-2016-inside-story-ofhow-labors-mediscare-plot-was-hatched/news-story/51 ee $0223 \mathrm{bfe} 1 \mathrm{fo}$ 922cd6d15f447e692f

Wright, Malcolm, David Farrer and Deborah Russell. 2013. 'Polling accuracy in a multiparty election'. International Journal of Public Opinion Research 26(1): 113-24. doi.org/10.1093/ijpor/edt009 
This text is taken from Double Disillusion: The 2016 Australian Federal Election, edited by Anika Gauja, Peter Chen, Jennifer Curtin and Juliet Pietsch, published 2018 by ANU Press, The Australian

National University, Canberra, Australia.

doi.org/10.22459/DD.04.2018.06 